\title{
Efeito alelopático de melissa, capim-cidreira, lavanda e alecrim na germinação e vigor de sementes de alface
}

\author{
Daniela Aparecida Teixeira * \\ Filipe Pereira Giardini Bonfim \\ Faculdade de Ciências Agronômicas, Universidade Estadual Paulista, Campus Botucatu Portaria I \\ Rua José Barbosa de Barros, 1780, CEP 18.610-307, Botucatu - SP, Brasil \\ * Autor para correspondência \\ daniela.teixeira@hotmail.com
}

Submetido em 28/04/2014

Aceito para publicação em 29/09/2014

\section{Resumo}

Objetivou-se, neste estudo, avaliar a influência na germinação e vigor de sementes de alface (Lactuca sativa L.) de macerados e infusões de Melissa officinalis L. (melissa), Rosmarinus officinalis L. (alecrim), Lavandula angustifolia Mill. (lavanda) e Cymbopogon citratus (DC.) Stapf. (capim-cidreira). O delineamento estatístico utilizado foi inteiramente casualizado, com nove tratamentos e quatro repetições, cada unidade experimental constituída por 25 sementes. Sendo os tratamentos: alecrim infusão, alecrim macerado, lavanda infusão, lavanda macerado, melissa infusão, melissa macerado, capim-cidreira infusão, capim-cidreira macerado e testemunha. As variáveis avaliadas foram: índice de velocidade de germinação (IVG), porcentagens de plantas anormais (PA), porcentagens de plantas germinadas (PG), massa fresca (MF), massa seca (MS), comprimento da parte aérea (CPA) e comprimento da radícula (CR). O capim-cidreira apresentou efeito alelopático negativo na germinação e no vigor de sementes de $L$. sativa L. Já em melissa infusão verificou-se ação estimulante.

Palavras-chave: Efeito alelopático; Germinação; Vigor

\section{Abstract}

Allelopathic effect of melissa, lemongrass, lavender and rosemary on germination and vigor of lettuce seeds. The objective of this study was to evaluate the influence of four herbal plants on the germination and vigor of lettuce seeds, using aqueous preparations and teas of Melissa officinalis L. (melissa), Rosmarinus officinalis L. (rosemary), Lavandula angustifolia Mill. (lavender) and Cymbopogon citratus (DC.) Stapf. (lemongrass). A randomized complete block design was used with 9 treatments and 4 repetitions. The treatments were: melissa tea, melissa aqueous preparation, rosemary tea, rosemary aqueous preparation, lavender tea, lavender aqueous preparation, lemongrass tea, lemongrass aqueous preparation and control. The variables evaluated were: germination speed index, percentage of abnormal plants, percentage of germinated plants, fresh matter, dry matter, shoot length and radicle length. Lemongrass showed negative allelopathic effects on germination and vigor of L. sativa L. Melissa tea had a stimulatory effect.

Key words: Allelopathic effect; Germination; Vigor 


\section{Introdução}

O termo alelopatia é definido, como efeito que direto ou indiretamente, de maneiras benéficas ou danosas, uma planta exerce sobre outra, perante produção de compostos químicos que são liberados no ambiente (SILVA et al., 2007; GOLDFARB et al., 2009). Esse fenômeno que ocorre largamente em comunidades de plantas, é um importante fator de manejo de culturas, pelo uso de plantas que exercem controle sobre determinadas espécies indesejadas, obtendo assim sistemas de culturas mais produtivos (GOLDFARD et al., 2009).

Os compostos alelopáticos liberados por uma planta podem afetar o crescimento, prejudicar o desenvolvimento normal e até mesmo inibir a germinação das sementes de outras espécies vegetais (ROSA et al., 2007). Podem também interferir diretamente no crescimento e no metabolismo vegetal, envolvem alterações em nível citológico, fitormonal, nos processos respiratórios e fotossintéticos, na síntese de proteínas, na quebra e reestruturação lipídica e de ácidos orgânicos, no estímulo ou inibição dos processos enzimáticos específicos e até mesmo nos efeitos sobre a relação hídrica e sobre a síntese de ácidos nucleicos nas plantas (BORELLA et al., 2010).

Pesquisas têm mostrado os efeitos dos extratos aquosos e dos óleos essenciais sobre a germinação de diferentes espécies (ALVES et al., 2004; MARASCHINSILVA; AQUILA, 2006; SOUZA-FILHO, 2006; PICCOLO et al., 2007). Na maioria das espécies, o efeito alelopático é mais evidente quando utilizados extratos de folhas (SOUZA et al., 2007).

Através da alelopatia, também, é possível escolher as espécies que serão utilizadas em sistemas de consórcio, método comum entre agricultores de regiões tropicais do mundo, onde se planta, simultaneamente numa mesma área, duas ou mais espécies cultivadas (BEZERRA et al., 2007). Esta prática vem substituindo a produção por monocultura de alguns cultivos, pois proporciona uma melhor produtividade e, é mais rentável (REJILA; VIJAYAKUMAR, 2011). Com base nessas informações pode-se utilizar como alternativa o consórcio de hortaliças e medicinais.
A melissa, conhecida como erva-cidreira verdadeira, também possui outros nomes populares como chá-defrança, cidrilha, citronela menor, erva-luísa, e melissa romana (CORREA JÚNIOR et al., 1991; COUTO, 2006) possui propriedades bioativas incluem atividade sedativa (BLANK et al., 2005), antiespamódicas, carminativas, estomáquicas, diaforéticas, antidrepressivas e vermífugas (REIS et al., 2009). A espécie R. officinalis L., conhecida popularmente como alecrim é utilizada na indústria alimentícia pelas propriedades antioxidantes de seus diterpenos. Estimulante digestivo, para a falta de apetite (inapetência); contra azia; em problemas respiratórios e debilidade cardíaca (cardiotônico) (LOW et al., 1999).

A lavanda pertencente à família Lamiaceae é considerada uma planta aromática, usada em perfumaria e medicina doméstica (GEMTCHÚJNICOV, 1976).

O capim-cidreira apresenta atividade farmacológica para vários distúrbios, tais como insônia, nervosismo, má-digestão, flatulência além de antiespasmódico de tecidos uterinos e intestinais, diaforético, antitérmico, diurético, antialérgico e analgésico (AKISUE et al., 1996; MING et al., 1996). Na agricultura tem sido empregado em curvas de nível das lavouras (LEAL et al., 2003). Sousa et al. (1991) relataram suas propriedades inseticidas, principalmente larvicida e repelente de insetos.

Visto que as sementes são excelentes organismos para bioensaios, pois, quando são reidratadas elas entram em processo de germinação, onde sofrem rápidas mudanças fisiológicas e tornam-se altamente sensíveis ao estresse ambiental, o presente trabalho, tem como objetivo avaliar os efeitos alelopáticos das plantas de melissa, capim-cidreira, lavanda, e alecrim na germinação e vigor de sementes de alface, identificando as espécies medicinais que tenham ação estimulante e inibitória em demais vegetais.

\section{Material e Métodos}

O experimento foi conduzido no Laboratório de Plantas Medicinais do Departamento de Horticultura, da Universidade Estadual Júlio de Mesquita Filho, no município de Botucatu, estado de São Paulo, coordenadas 
geográficas $22^{\circ} 52^{\prime} 47^{\prime}$ 'S, $48^{\circ} 25^{\prime}$ '12'W, Brasil, no mês de setembro de 2013.

Os macerados de alecrim, melissa, lavanda e capimcidreira foram obtidos da parte aérea fresca, triturada em liquidificador, durante 5 minutos, na proporção de 100 $\mathrm{g}$ de folhas frescas em $1 \mathrm{~L}$ de água destilada, conforme Barreiro et al. (2005), sendo então filtrado. O preparo da infusão foi feito com $100 \mathrm{~g}$ de folhas frescas imersas e abafadas por 5 minutos em 1 L de água destilada fervida. O delineamento utilizado foi o inteiramente casualizado, com nove tratamentos e quatro repetições, cada parcela experimental constituída por 25 sementes. Os tratamentos foram: testemunha (água destilada, caracterizada por concentração de $0 \%$ ), o macerado e a infusão de capim-cidreira, melissa, lavanda e alecrim em $100 \%$ de concentração.

Os aquênios de alface, foram colocados em caixas do tipo "gerbox" com papel germitest umedecido com $8 \mathrm{~mL}$ dos macerados e infusão correspondente aos tratamentos, mantidas a $20^{\circ} \mathrm{C}$, fotoperíodo de $12 \mathrm{~h}$ luz e $12 \mathrm{~h}$ escuro, por 14 dias. Os testes de germinação e vigor seguiram recomendações e critérios estabelecidos pelo Ministério da Agricultura (BRASIL, 2009).

As variáveis analisadas foram: índice de velocidade germinação (IVG), porcentagem de plantas anormais (PA), porcentagem de germinação (PG), matéria da planta fresca (MF), matéria planta seca (MS), comprimento da parte aérea (CPA) e comprimento da radícula $(\mathrm{CR})$.

O índice de velocidade de germinação foi determinado ao $14^{\circ}$ dia após a semeadura, avaliando-se o número de plântulas normais. A determinação do índice de velocidade de germinação foi conduzida conforme Maguire (1962),

$$
\mathrm{IVG}=\mathrm{G}_{1} / \mathrm{N}_{1}+\mathrm{G}_{2} / \mathrm{N}_{2}+\mathrm{G}_{3} / \mathrm{N}_{3}+\ldots+\mathrm{G}_{\mathrm{n}} / \mathrm{N}_{\mathrm{n}}
$$

Onde: $\mathrm{G}_{1}, \mathrm{G}_{2}, \mathrm{G}_{3}, \ldots, \mathrm{G}_{\mathrm{n}}=$ número de sementes germinadas no dia da observação.

$\mathrm{N}_{1}, \mathrm{~N}_{2}, \mathrm{~N}_{3}, \ldots, \mathrm{N}_{\mathrm{n}}=$ número de dias após a semeadura.

Os dados das variáveis foram transformados para $\sqrt{X}+0,5$, com exceção das porcentagens. Os resultados foram submetidos à análise no programa ASSISTAT.

\section{Resultados}

A análise de variância mostra que as variáveis determinadas (IVG), (PG), (MF), (CPA) e (CR), apresentaram diferenças estatísticas em função dos tratamentos (Tabelas 1 e 2).

TABELA 1: Resumo da análise de variância índice de velocidade de germinação(IVG), de porcentagem de germinação (\%PG) e Porcentagem de plantas anormais (\%PA) de sementes de alface submetidas a tratamentos alelopáticos ou não (testemunha) com macerados e infusões das plantas de melissa, capim cidreira, lavanda e alecrim.

\begin{tabular}{lcccc} 
Fonte de & Graus de & \multicolumn{3}{c}{ Quadrados médios } \\
\cline { 3 - 5 } \multicolumn{1}{c}{ variação } & liberdade & IVG & PG & PA \\
\hline Tratamento & 8 & $3,5145^{* *}$ & $4,9432^{* *}$ & $1,1130^{\text {ns }}$ \\
Resíduo & 27 & 0,47938 & 674,657 & 552,768 \\
\hline Coeficiente de variação (\%) & 42,42 & 55,29 & 34,1 \\
\hline
\end{tabular}

** Significativo a $1 \%$ de probabilidade, respectivamente, pelo teste F; * Significativo a $5 \%$ de probabilidade, respectivamente, pelo teste F; ns Não significativo.

TABELA 2: Resumo da análise de variância índice de comprimento de radícula (CR) e comprimento da parte aérea, massa seca (MS) e massa fresca (MF) de sementes de alface submetidas a tratamentos alelopáticos ou não (testemunha) com macerados e infusões das plantas de melissa, capim cidreira, lavanda e alecrim.

\begin{tabular}{lccccc}
\hline \multirow{2}{*}{$\begin{array}{l}\text { Fonte de } \\
\text { variação }\end{array}$} & Graus de & \multicolumn{4}{c}{ Quadrados médios } \\
\cline { 2 - 6 } liberdade & MS & MF & CPA & CR \\
\hline Tratamento & 8 & $1,2496^{\text {ns }}$ & $5,0899^{* *}$ & $4,4507^{* *}$ & $4,7627^{* *}$ \\
Resíduo & 27 & 0,0044 & 0,00470 & 0,11223 & 0,10766 \\
\hline $\begin{array}{l}\text { Coeficiente de variação } \\
\text { (\%) }\end{array}$ & 2,90 & 8,66 & 27,67 & 24,78 \\
\hline
\end{tabular}

** Significativo a $1 \%$ de probabilidade, respectivamente, pelo teste F. ${ }^{\text {ns }}$ Não significativo.

No IVG observou-se média superior no tratamento testemunha, e média inferior nos dois tratamentos capimcidreira e em lavanda infusão. Na variável PG, o tratamento melissa infusão teve média superior na taxa de germinação quando comparado com os dois tratamentos com capimcidreira e com lavanda infusão. $\mathrm{O}$ capim infusão teve menor média em relação a testemunha, evidenciando efeito alelopático negativo (Tabela 3). Para PA, não foi observado diferença significativas dos tratamentos (Tabela 1). 
No CPA, o tratamento capim infusão, obteve média inferior, em comparação à lavanda infusão, melissa infusão e aos dois tratamentos com alecrim, porém nenhum desses diferiu significativamente da testemunha. Para CR, observou-se média superior no tratamento melissa infusão, em relação à testemunha. $\mathrm{Na} \mathrm{MF}$, houve média superior no tratamento melissa infusão, quando comparado com melissa macerado, lavanda infusão, aos dois tratamentos utilizando capim-cidreira e testemunha (Tabela 4).

TABELA 3: Valores médios de porcentagem de germinação (PG) e índice de velocidade de germinação (IVG) de sementes alface com tratamento alelopático ou não (testemunha).

\begin{tabular}{lcc}
\hline \multicolumn{1}{c}{ Tratamentos } & PG (\%) & IVG (dias) \\
\hline Alecrim Infusão & $72,00 \mathrm{ab}$ & $1,67105 \mathrm{ab}$ \\
Alecrim Macerado & $43,00 \mathrm{abcd}$ & $1,89158 \mathrm{ab}$ \\
Lavanda Infusão & $9,00 \mathrm{~cd}$ & $0,96836 \mathrm{~b}$ \\
Lavanda Macerado & $53,00 \mathrm{abcd}$ & $1,70104 \mathrm{ab}$ \\
Melissa Infusão & $79,00 \mathrm{a}$ & $1,99108 \mathrm{ab}$ \\
Melissa Macerado & $31,25 \mathrm{abcd}$ & $1,79716 \mathrm{ab}$ \\
Capim cidreira Infusão & $0,00 \mathrm{~d}$ & $0,70711 \mathrm{~b}$ \\
Capim cidreira Macerado & $12,00 \mathrm{bcd}$ & $1,08571 \mathrm{~b}$ \\
Testemunha & $64,00 \mathrm{abc}$ & $2,87513 \mathrm{a}$ \\
\hline
\end{tabular}

As médias seguidas de pelo menos uma mesma letra minúscula na coluna, não diferem significativamente entre si pelo teste de Tukey a $5 \%$ de probabilidade.

TABELA 4: Valores médios de Massa fresca (MF), comprimento da parte aérea (CPA) e comprimento da radícula (CR) de sementes alface com tratamento alelopático ou não (testemunha).

\begin{tabular}{lccc}
\multicolumn{1}{c}{ Tratamentos } & MF (g) & CPA (cm) & CR (cm) \\
\hline Alecrim Infusão & $0,8484 \mathrm{ab}$ & $1,54067 \mathrm{ab}$ & $1,55601 \mathrm{ab}$ \\
Alecrim Macerado & $0,8323 \mathrm{ab}$ & $1,69357 \mathrm{a}$ & $1,59807 \mathrm{ab}$ \\
Lavanda Infusão & $0,7203 \mathrm{~b}$ & $1,69357 \mathrm{a}$ & $1,30887 \mathrm{abc}$ \\
Lavanda Macerado & $0,8509 \mathrm{ab}$ & $0,84951 \mathrm{bc}$ & $1,17341 \mathrm{abc}$ \\
Melissa Infusão & $0,9324 \mathrm{a}$ & $1,62633 \mathrm{ab}$ & $1,95015 \mathrm{a}$ \\
Melissa Macerado & $0,7435 \mathrm{~b}$ & $0,98336 \mathrm{abc}$ & $1,09960 \mathrm{bc}$ \\
Capim cidreira Infusão & $0,7071 \mathrm{~b}$ & $0,70711 \mathrm{c}$ & $0,70711 \mathrm{c}$ \\
Capim cidreira Macerado & $0,7263 \mathrm{~b}$ & $1,32274 \mathrm{abc}$ & $1,39812 \mathrm{abc}$ \\
Testemunha & $0,7632 \mathrm{~b}$ & $1,13832 \mathrm{abc}$ & $1,12726 \mathrm{bc}$ \\
\hline
\end{tabular}

As médias seguidas de pelo menos uma mesma letra minúscula na coluna, não diferem significativamente entre si pelo teste de Tukey a $5 \%$ de probabilidade.

\section{Discussão}

Para Ferreira e Borghetti (2004), quanto maior o índice de velocidade de germinação maior é o vigor das sementes. Esse índice se relaciona com os números de plântulas/dia. Para esses mesmos autores, quanto menor a velocidade de germinação maior é o vigor, pois quantifica o número de sementes germinadas/dia. O que se verificou nesse experimento foi que os extratos de capim-cidreira infusão e macerado e lavanda infusão atuaram diminuindo o vigor o que indica interferência desses tratamentos na germinação das sementes de alface.

Segundo Rodrigues e Lopes (1999), os compostos alelopáticos são inibidores de germinação e crescimento, pois interfere na divisão celular, permeabilidade de membranas e na ativação de enzimas. Lustosa et al. (2007) observaram que para a variável porcentagem de germinação, tanto o extrato aquoso de Piper aduncum L. quanto o de Piper tectoniifolium Kunth mostraram efeito alelopático significativo sobre as sementes de alface. $\mathrm{O}$ mesmo foi verificado nesse bioensaio com o tratamento capim-cidreira infusão.

Segundo Hoffmann et al. (2007), sementes de picão-preto tiveram o comprimento radicular e da parte aérea reduzidos significativamente, à medida que se aumentaram as concentrações de extratos aquosos de espirradeira (Nerium oleander L.). MaraschinSilva e Aquila (2006) constataram que as plântulas de alface tiveram reduções acentuadas no comprimento radicular quando submetidas a extratos de Erythroxylum argentinum O.E.Schulz e Ocotea puberula (Rich.) Nees, extratos de Luehea divaricata Mart. \& Zucc. e Myrsine guianensis (Aubl.) Kuntze embora tenham provocado reduções no comprimento radicular, as respostas não foram acentuadas. Esses resultados não corroboram com o visto nesse experimento, uma vez que melissa infusão estimulou o crescimento da radícula.

Em trabalho realizado por Silveira et al. (2010) os tratamentos influenciaram as massas secas da parte aérea e das raízes das plântulas de tiririca. Extratos de Lippia sidoides L. em concentrações maiores inibiram o desenvolvimento de radicelas. Isso ocorre, devido a alelopatia negativa dos tubérculos de tiririca quando 
expostos ao extrato do alecrim pimenta. O mesmo não pode ser verificado nesse trabalho, uma vez que melissa infusão promoveu incremento nas médias desta variável quando comparada com a testemunha.

Especificamente entre aqueles constituintes químicos de óleo essencial com atividade alelopática já comprovada e que podem estar envolvidos nos efeitos observados neste trabalho, isoladamente ou em associação com outros componentes, estão o limoneno, a cânfora e o linalol (FISCHER, 1991; VOKOU et al., 2003) presentes em grande quantidade no capimcidreira, o qual mostrou alelopatia negativa para a porcentagem de germinação.

O potencial alelopático desses compostos pode ser identificado por meio de extratos aquosos e/ou alcoólicos derivados tanto de plantas cultivadas quanto de medicinais. Trabalhos nesse sentido apontam que houve atividade alelopática e citotóxica dos extratos aquosos de espinheira-santa (Maytenus ilicifolia Mart.) sobre sementes de alface (SOUZA et al., 2005). O extrato metanólico das folhas de Caryocar brasiliense Camb, apresentou ação inibitória em diferentes concentrações sobre a germinação de sementes de Panicum maximum Jacq., com valores de inibição variando de 50 até $75 \%$ (MOREIRA et al., 2009).

Portanto, conclui-se que os dois tratamentos de capim-cidreira demonstraram ter o maior potencial alelopático, sendo esse negativo na germinação e vigor de aquênios de alface, quando comparado com os outros tratamentos. No entanto, a ação estimulante pode ser verificada utilizando a melissa em infusão. Tais resultados permitem concluir a ação individual de cada espécie e do modo de preparo dos extratos aquosos. Investigações mais amplas, incluindo outras metodologias experimentais, principalmente testes em condições de campo, que evidenciem os efeitos de espécies com potencial alelopáticos são necessárias. Tal estudo torna-se de extrema importância, uma vez que a utilização destas espécies pode contribuir na inibição de plantas espontâneas e na determinação de manejos mais adequados.

\section{Referências}

AKISUE, G.; AKISUE, M. K.; SILVA, J. R.; ANDALUZ, M. I. Padronização da droga e do extrato fluido de Cymbopogon citratus (D.C.) Stapf. Lecta, Bragança Paulista, v. 14, n. 2, p. 109119, 1996.

ALVES, M. C. S.; FILHO, S. M; INNECCO, R.; TORRES, S. B. Alelopatia de extratos voláteis na germinação de sementes e no comprimento da raiz de alface. Pesquisa Agropecuária Brasileira, Brasília v. 39, n. 11, p. 1083-1086, 2004.

BARREIRO, A. P; DELACHIAVE, M. E. A.; SOUZA, F. S. Efeito alelopático de extratos de parte aérea de barbatimão [Stryphnodendron adstringens (Mart.) Coville] na germinação e desenvolvimento da plântula de pepino. Revista Brasileira de Plantas Medicinais, Botucatu, v. 8, n.1, p. 4-8, 2005.

BEZERRA, A. P. A.; PITOMBEIRA, J. B.; TÁVORA, F. J. A. F.; VIDAL NETO, F. C. Rendimento, componentes da produção e uso eficiente da terra nos consórcios sorgo $\mathrm{x}$ feijão-de-corda e sorgo x milho. Ciência Agronômica, Fortaleza, v. 38, n. 1, p. 104-108, 2007.

BLANK, A. F.; FONTES, S. M.; OLIVEIRA, A. S. O.; MENDONÇA, M. C.; SILVA-MANN, R.; ARRIGONI-BLANK, M. F. Produção de mudas, altura e intervalo de corte em melissa, Horticultura Brasileira, Brasília, v. 23, n. 3, p. 780-784, 2005.

BRASIL. Regras para análise de sementes. Brasília: Ministério da Agricultura, Pecuária e Abastecimento, 2009. 399 p.

BORELLA, J.; TUR, C. M.; PASTORINI, L. H. Atividade alelopática de extratos aquosos de folhas de Rollinia sylvatica sobre a germinação e o crescimento inicial do rabanete. Revista Biociências, Taubaté, v. 16, n. 2, p. 94-101, 2010.

CORREA JÚNIOR, C.; MING, L. C.; SCHEFFER, M. C. Cultivo de plantas medicinais, condimentares e aromáticas. Curitiba: EMATER-PR, 1991. $151 \mathrm{p}$.

COUTO, M. E. O. Coleção de plantas medicinais aromáticas e condimentares. 2006. Pelotas: Embrapa. Documento 157. Disponível em: <http://www.cpact.embrapa.br/publicacoes/ documentos/documento-157.pdf>. Acesso em: 23 maio 2014.

FERREIRA, A. G.; BORGHETTI, F. Germinação: do básico ao aplicado. Porto Alegre: Artmed, 2004. 323 p.

FISCHER, N. H. Plant terpenoids as allelopathy agents. In: HARBONE, J. B.; TOMES-BARBERAN, F. A. (Ed.). Ecological chemistry and biochemistry of plant terpenoids. Oxford: Clarendon, 1991. p. 377-399.

GEMTCHÚJNICOV, I. D. Manual de taxonomia vegetal: plantas de interesse econômico. São Paulo: Ed. Agronômica Ceres, 1976. $368 \mathrm{p}$.

GOLDFARB, M.; PIMENTEL, L. W.; PIMENTEL, N. W. Alelopatia: relações nos agroecossistemas. Tecnologia \& Ciência Agropecuária, João Pessoa, v. 3, n. 1, p. 23-28, 2009.

HOFFMANN, C. E. F.; NEVES, L. A. S.; BASTOS, C. F.; WALlAU, G. L. Atividade alelopática de Nerium Oleander L. e Dieffenbachia picta Schott em sementes de Lactuca Sativa L. e Bidens pilosa L. Revista de Ciências Agroveterinárias, Lages, v. 6, n. 1, p. 11-21, 2007.

LEAL, T.C.A.B.; FREITAS, S.P.; SILVA, J.F.; CARVALHO, A.J.C. Produção de biomassa e óleo essencial em plantas de capim cidreira 
[Cymbopogon citratus (DC.) Stapf] em diferentes idades. Revista Brasileira de Plantas Medicinais. Botucatu, v.5, n.1,p.61-64, 2003.

LOW, T.; RODD, T.; BERESFORD, R. Segredos e virtudes das plantas medicinais. Rio de Janeiro: Editora Reader's Digest, 1999. $416 \mathrm{p}$.

LUSTOSA, F. L. F.; OliVEIRA, S. C. C.; ROMEIRO, L. A. Efeito alelopático de extrato aquoso de Piper aduncum L. e Piper tectoniifolium Kunth na germinação e crescimento de Lactuca sativa L. Revista Brasileira de Biociências, Porto Alegre, v. 5, supl. 2, p. 849-851, 2007.

MAGUIRE, J. D. Speeds of germination-aid selection and evaluation for seedling emergence and vigor. Crop Science, Madison, v. 2, n. 2, p. 176-177, 1962.

MARASCHIN-SILVA, F.; AQUILA, M. E. A. Potencial alelopático de espécies nativas na germinação e crescimento inicial de Lactuca sativa L. (Asteraceae). Acta Botanica Brasilica, Feira de Santana, v. 20, n. 1, p. 61-69, 2006.

MING, L.C.; FIGUEIREDO, R.O.; MACHADO, S.R.; ANDRADE, R.M.C. Yield of essential oil of and citral content in different parts of lemongrass leaves (Cymbopogon citratus(DC.) Stapf) Poaceae. Acta Horticulturae, Bélgica, v. 1, n. 426, p. 555-559,1996.

MOREIRA, P. F. S. D.; SOUZA, D. R.; TERRONES, M. G. H. Avaliação do potencial alelopático do extrato metanólico obtido das folhas de Caryocar brasiliense Camb. (pequi) na inibição do desenvolvimento da raiz em sementes de Panicum maximum. Bioscience Journal, Uberlândia, v. 24, n. 2, p. 74-79, 2009.

PICCOLO, G.; ROSA, D. M.; MARQUES, D. S.; MAULI, M. M.; FORTES, A. M. T. Efeito alelopático de capim limão e sabugueiro sobre a germinação de guanxuma. Semina: Ciências Agrárias, Londrina, v. 28, n. 3, p. 381-386, 2007.

REJILA, S.; VIJAYAKUMAR, N. Allelopathic effect of Jatropha curcas on selected intercropping plants (Green Chilli and Sesame). Journal of Phytology, Humnabad, v. 5, n. 3, p. 1-3, 2011.

REIS, E. S.; PINTO, J. E. B. P.; ROSADO, L. D. S; CORRÊA, R. M. Teor e composição química do óleo essencial de Melissa officinalis L. in vitro sob a influência do meio de cultura. Acta Scientiarium Agronomy, Maringá, v. 31, n. 2, p. 331-335, 2009.

RODRIGUES, F. C. M. P.; LOPES, B. M. Potencial alelopático de Mimosa caesalpinaefolia Benth sobre sementes de Tabebuia alba (Cham.) Sandw. Série Técnica Floresta e Ambiente, Rio de Janeiro, v. 8, n. 1, p. 130-136, 1999.
ROSA, D.; FORTES, A.; PALMA, D.; MARQUES, D.; CORSATO, J.; LESZCZYNSKI, R.; MAULI, M. Efeito dos extratos de tabaco, leucena e sabugueiro sobre a germinação de Panicum maximum Jaqc. Revista Brasileira de Biociências, Porto Alegre, v. 5, n. 1, p. 444-446, 2007.

SILVA, J. P.; DUCCINI, C. S.; SOUZA, E. C.; NEVES, V. C.; PASIN, L. A. P. Efeito alelopático in vitro de Malva sylvestris e Artemisia camphorata na germinação e desenvolvimento de sementes de petúnia (Petunia integrifolia). In: CONGRESSO DE ECOLOGIA DO BRASIL, 8, 2007, Caxambu. Anais... Vol. 1. Caxambu: SBE, 2007. p. 1-2.

SILVEIRA, H. R. O.; FERRAZ, E. O.; MATOS, C. C.; ALVARENGA, I. C. A.; GUILHERME, D. O.; TUFFI SANTOS, L. D.; MARTINS, E. R. Alelopatia e homeopatia no manejo da tiririca (Cyperus rotundus). Planta Daninha, Viçosa, v. 28, n. 3, p. 499-506, 2010.

SOUSA, M. P.; MATOS, M. E. O.; MATOS, F. J. A.; MACHADO, M. I. L.; CRAVEIRO, A. A. Constituintes químicos ativos de plantas medicinais brasileiras. Fortaleza: Edições UFC, Laboratório de Produtos Naturais, 1991. 416 p.

SOUZA, C. S. M.; SILVA, W. L. P.; GUERRA, A. M. N. M.; CARDOSO, M. C. R.; TORRES, S. B. Alelopatia do extrato aquoso de folhas de aroeira na germinação de sementes de alface. Revista Verde, Mossoró, v. 2, n. 2, p. 96-100, 2007.

SOUZA, S. A. M.; CATTELAN, L. V.; VARGAS, D. P.; PIANA, C. F. B.; BOBROWSKI, V. L.; ROCHA, B. H. G. Efeito de extratos aquosos de plantas medicinais nativas do Rio Grande do Sul sobre a germinação de sementes de alface. Ciências Biológicas e da Saúde, Ponta Grossa, v. 11, n. 3, p. 29-38, 2005.

SOUZA-FILHO, A. P. S.; SANTOS, R. A.; SANTOS, L. S.; GUILHON, G. M. P.; SANTOS, A. S.; ARRUDA, M. S. P.; MULLER, A. H.; ARRUDA, A. C. Potencial alelopático de Myrcia guianensis. Planta Daninha, Viçosa, v. 24, n. 4, p. 649-656, 2006.

VOKOU, D.; DOUVLI, P.; BLIONIS, G. J.; HALLEY, J. M. Effects of monoterpenoids, acting alone or in pairs, on seed germination and subsequent seedling growth. Journal of Chemical Ecology, Tampa, v. 29, n. 10, p. 2281-2301, 2003. 